\title{
Effect of Low-Pressure on Diesel Engine Emission Characteristics
}

\author{
Xianyi Jiang', Yang Zhao ${ }^{1}$, Chengbin Zhang1 \\ ${ }^{1}$ Key Laboratory of Energy Thermal Conversion and Control of Ministry of Education, \\ School of Energy and Environment, Southeast University, Nanjing 210096, China, \\ 213153162@seu.edu.cn; 850626792@qq.com; cbzhang@seu.edu.cn
}

\section{Extended Abstract}

Numerous scientific explorations activities, such as ice core survey and astronomical observation, have been conducted at the Antarctic research station, which is supported by diesel engines. Nonetheless, emissions of diesel engines contain a large amount of fine particulate matter. Under the action of the wind field, these particulate matters diffuse into the atmosphere, which may reduce the atmospheric transparency, and ultimately affect the astronomical observation. Meantime, they may shorten the service life of the experimental equipment and even resulted in malfunction. In addition, considering the particularity of the Antarctic environment, the fuel in the cylinder will be more difficult to combust completely, which will obviously influence the emission of diesel engines. Therefore, research on the emission characteristics of diesel engines in a low-pressure condition has guiding significance for constructing the Antarctic research station.

The emission characteristics of diesel engines were affected by various factors, included atmospheric pressure, combustion temperature, fuel type, etc. In the past few decades, numerous studies on the performance and emission characteristics of diesel engines under normal pressure have been performed. Nevertheless, few researchers studied the emission characteristics in a low-pressure environment like the Antarctic. Thus, a low-pressure simulation platform has been designed and built. An experiment was designed to study the effect of low pressure on emission characteristics of diesel engines.

Conclusively, this experiment studied the emission characteristics of diesel engines in a low-pressure environment, especially the relationship between the concentration of components and experimental conditions, which included engine speed, atmospheric pressure, and fuel type. The results showed that: (1) as the atmospheric pressure decreased, the concentrations of carbon monoxide in exhaust increased. Particularly, for lower atmospheric pressure, the results showed that the concentrations of carbon monoxide present a sharply rising trend. The concentrations of hydrocarbon decreased first and then increased. The concentrations of nitrogen oxide decreased while the particulate matter emissions increased, (2) under ordinary pressure, engine speed has no significant effect on the concentration of carbon monoxide. While under lowpressure condition, the concentrations of carbon monoxide increased as the engine speed increased. And as the engine speed increased, the concentrations of hydrocarbon in exhaust decreased first and then increased. Meanwhile, the concentrations of nitrogen oxide decreased. The concentrations of particulate matter decreased first and then increased. Particularly, the concentrations of particulate matter reached a minimum value when the engine speed was $2400 \mathrm{rpm}$. Compared with ordinary pressure, the relationship between the concentrations of carbon monoxide and the engine speed tends to be more visible and explicit under low pressure, (3) compared to general diesel fuel, using jet fuel for diesel engines effectively reduced the concentrations of carbon monoxide and particulate matter under the same condition. However, the concentrations of nitrogen oxide were higher than the one which uses general diesel fuel. Under low-pressure condition, the concentrations of particulate matter in exhaust were six times higher than the one of Euro V emissions standard when the engine speed was $3600 \mathrm{rpm}$. 